\title{
JNK signaling in hepatocarcinoma cells is associated with the side population upon treatment with anticancer drugs
}

\author{
JONG BIN KIM ${ }^{1 *}$, SEO-YOUNG PARK ${ }^{2 *}$, HYE RI KIM $^{1}$, YEON HWA AHN $^{1}$, HYEON-GUN JEE $^{3}$, \\ JEONG-HOON LEE ${ }^{1}$, SU JONG YU ${ }^{1}$, HYO-SUK LEE ${ }^{1}$, MINJONG LEE ${ }^{1}$, \\ JUNG-HWAN YOON $^{1}$ and YOON JUN KIM ${ }^{1}$ \\ ${ }^{1}$ Department of Internal Medicine and Liver Research Institute, Seoul National University College of Medicine; \\ ${ }^{2}$ Biomedical Research Institute, Seoul National University Hospital; ${ }^{3}$ Cancer Research Institute, \\ Seoul National University College of Medicine, Jongno-gu, Seoul 110-799, Republic of Korea
}

Received October 25, 2013; Accepted May 15, 2014

DOI: $10.3892 / \mathrm{mmr} .2014 .2761$

\begin{abstract}
Liver cancer is one of the most drug-resistant cancer types, and cancer stem cells are related to drug resistance. c-Jun-N-terminal kinase (JNK) signaling is involved in drug resistance, and the side population of cells (SP cells) can be used as a model to study liver cancer stem cells. We sought to evaluate the relationship between SP cells and JNK signaling in hepatocarcinoma cells. For this purpose, we examined cell proliferation and the SP cell ratio following treatment of Huh7 cells with the anticancer drugs 5-fluorouracil (5-FU) and paclitaxel. The expression of phospho-stress-activated protein kinase (SAPK)/JNK in the treated cells was evaluated using immunoblotting. 5-FU and paclitaxel treatment increased the number of SP cells and JNK phosphorylation, and decreased cell survival. Huh7 and HepG2 cells were also treated with SP600125, a JNK inhibitor, to study the relationship between SP cells and JNK signaling. The increase in the number of SP cells and the SAPK/JNK and c-Jun phosphorylation was reverted by SP600125 treatment in these cells. We also used immunohistochemistry and showed that SAPK/JNK and c-Jun phosphorylation are increased in hepatocarcinoma tissues. In conclusion, our results demonstrate that the number of SP cells and SAPK/JNK phosphorylation are increased upon treatment with anticancer drugs, and that this increase is blocked by inhibition of JNK signaling. These findings suggest that drug resistance in liver cancer may involve an increase in the number of SP cells following JNK activation.
\end{abstract}

Correspondence to: Professor Yoon Jun Kim, Department of Internal Medicine and Liver Research Institute, Seoul National University College of Medicine, 103 Daehak-ro, Jongno-gu, Seoul 110-799, Republic of Korea

E-mail: yoonjun@snu.ac.kr

*Contributed equally

Key words: liver cancer, JNK, Huh7 cells, cancer stem cells, side population, drug resistance

\section{Introduction}

Cancer is predominantly caused by mutations, germ-line or somatic, without any separation of cell type observed for a long period. It is known that certain stem cells are associated with the occurrence of cancer. These cells are called cancer stem cells because of their tumor-initiating and drug resistance properties (1). Isolation of cancer stem cells from hepatocellular carcinoma (HCC) was previously reported (2).

A number of methods have been used to study cancer stem cells, including cell sorting using specific surface markers (3), culture of sphere-forming cells (4) and analyses of the side population (SP) (5), defined as cells capable of efficient Hoechst 33342 dye efflux (6). SP cells can be used as a model to study stem cells because of their self-renewing, differentiating (7) and tumor-initiating abilities (8). SP cells identified in liver cancer initiated tumors (9), expressed high levels of ABCG2 transporters (10), and expressed a marker of hepatocarcinoma stem cells, CD133. Because of these properties, these SP cells were suggested to be liver cancer stem cells (9), and to associate with the high drug resistance of liver cancer. Treatment with anticancer drugs such as doxorubicin, 5-fluorouracil (5-FU), and gemcitabine, increases the SP cell number. In addition, SP cells are known to relate to the drug resistance of liver cancer associated with transporters (11).

c-Jun-N-terminal kinase (JNK) signaling in SP cells was previously associated with drug resistance in liver cancer (12). JNK signaling maintains proliferation and migration in healthy stem cells (13), and is essential for liver regeneration processes (14). In contrast to healthy liver cells, JNK signaling inhibits survival and growth in liver cancer cells upon activation of c-Jun (15). To date, the relationship between SP cells, drug resistance, and JNK signaling in liver cancer is unclear.

In this study, we used the hepatocarcinoma cell lines Huh7 and HepG2 to study the relationship between increased numbers of SP cells and the signaling molecules involved in this interaction. We analyzed the fraction of SP cells during and after treatment with anticancer drugs, and examined cell survival rates and expression of relevant signaling molecules. 


\section{Material and methods}

Cell cultures. Huh7 and HepG2 cells were obtained from the Korean Cell Line Bank (Seoul, Korea). The cells were cultured in Gibco ${ }^{\circledR}$ Dulbecco's modified Eagle's medium (DMEM) containing 10\% Gibco $^{\circledR}$ fetal bovine serum (FBS), both purchased from Thermo Fisher Scientific (Waltham, MA, USA). To obtain cultures of adherent cells, $5 \times 10^{5}$ cells were seeded on Falcon ${ }^{\circledR}$ tissue culture dishes (Corning, Tewksbury, MA, USA). All cultures were maintained at $37^{\circ} \mathrm{C}$ in a humidified $5 \% \mathrm{CO}_{2}$ atmosphere.

Cell survival rates after anticancer drug treatment. Huh7 cells were seeded $\left(5 \times 10^{5}\right.$ cells $)$ in DMEM containing $10 \%$ FBS. After $24 \mathrm{~h}$, the cells were washed twice with phosphate-buffered saline (PBS; Gibco-BRL, Carslbad, CA, USA) and fresh medium was added. The cells were treated for $72 \mathrm{~h}$ with distilled water (control), 1,10 or $100 \mu \mathrm{M} 5$-FU, or 1,10 or $100 \mathrm{nM}$ paclitaxel (both from Sigma-Aldrich, St. Louis, MO, USA). The survival rate was estimated as the number of viable cells, counted in a Neubauer chamber (Millipore, Temecula, CA, USA) at different time-points, as the cells that were positively stained with the Trypan blue dye (0.4\%; Gibco-BRL). Selected cells treated with $10 \mu \mathrm{M}$ 5-FU or $10 \mathrm{nM}$ paclitaxel were used to observe SP cells and JNK expression following drug treatment.

SP cell analyses. Huh7 cells were seeded as described above. The cells were treated with distilled water (control), $10 \mu \mathrm{M}$ 5 -FU, or $10 \mathrm{nM}$ paclitaxel for $72 \mathrm{~h}$. SP cell analyses were performed as previously described (16). Briefly, cells were detached and collected as cell pellets. To analyze the SP fraction, $1 \times 10^{6}$ cells $/ \mathrm{ml}$ were incubated with the Hoechst 33342 dye ( $5 \mu \mathrm{g} / \mathrm{ml}$; Sigma-Aldrich, St. Louis, MO, USA) in DMEM containing $10 \% \mathrm{FBS}$, with vortexing for $90 \mathrm{~min}$ at $37^{\circ} \mathrm{C}$. Cells were also incubated with the Hoechst dye and 50-100 $\mu \mathrm{M}$ verapamil (Sigma-Alrdich), an efflux blocker, to confirm the SP cell population. At the end of the incubation, cells were centrifuged at $320 \mathrm{xg}$ at $4{ }^{\circ} \mathrm{C}$ and collected for analyses of the SP fraction. Propidium iodide $(1 \mu \mathrm{g} / \mathrm{ml}$; Sigma-Aldrich $)$ was added prior to fluorescence-activated cell sorting (FACS) analysis, in order to allow identification and exclusion of dead cells. Samples were analyzed using a FACS Aria instrument (BD Biosciences, Franklin Lakes, NJ, USA).

Phospho-stress-activated protein kinase ( $p$-SAPK)/JNK immunoblotting. Huh7 cells were seeded as described above. The cells were treated for $72 \mathrm{~h}$ with distilled water (control), $10 \mu \mathrm{M} 5-\mathrm{FU}$, or $10 \mathrm{nM}$ paclitaxel. Total cell lysates were prepared in $100 \mu \mathrm{l}$ Cell Lysis buffer(Cell Signaling Technology, Beverly, MA, USA). Protein concentrations were measured using a Protein Assay kit (Bio-Rad Laboratories, Hercules, CA, USA). Equal amounts of cell lysates were separated using $10 \%$ sodium dodecyl sulfate-polyacrylamide gel electrophoresis (SDS-PAGE), and proteins were electrotransferred onto Hybond-ECL nitrocellulose membranes (Amersham Biosciences, Buckinghamshire, UK). Blots were blocked for $1 \mathrm{~h}$ with blocking buffer and incubated overnight at $4^{\circ} \mathrm{C}$ with mouse monoclonal anti-p-SAPK/JNK (dilution, 1:1,000, Thr183/Tyr185; Cell Signaling Technology) and anti- $\beta$-actin (dilution, 1:1,000; Santa Cruz Biotechnology, Inc., Santa Cruz, CA, USA) immunoglobulin G (IgG). Blots were washed with $0.02 \%$ Tris-buffered saline with Tween 20 (Sigma-Alrdich) and incubated for $1 \mathrm{~h}$ at room temperature with goat anti-mouse IgG (H+L; 1:2,500; Jackson ImmunoResearch Laboratories, West Grove, PA, USA). Labeled proteins were detected using an enhanced chemiluminescence detection system (Amersham Biosciences).

p-SAPK/JNK, c-Jun and phospho-c-Jun (p-c-Jun) expression after treatment with anticancer drugs and SP600125. Huh7 and HepG2 cells were seeded as described above. Cells were treated for $72 \mathrm{~h}$ with distilled water and dimethyl sulfoxide (DMSO; control; Sigma-Aldrich), $10 \mu \mathrm{M}$ SP600125 (SigmaAldrich), $10 \mu \mathrm{M}$ 5-FU, or $10 \mu \mathrm{M}$ SP600125 and $10 \mu \mathrm{M}$ 5-FU. The SP fraction, cell survival, expression of p-SAPK/JNK, c-Jun, and p-c-Jun were measured as described above. c-Jun and p-c-Jun expression were analyzed using c-Jun and p-c-Jun mouse monoclonal IgGs (both at 1:1,000; Cell Signaling Technology).

HCC tissue immunohistochemistry. The Institutional Review Board of the Seoul National University Hospital approved the use of human tissues. The tissues were collected from six liver cancer patients who had surgery at the Seoul National University Hospital. Tissues were embedded with paraffin, cut into 3- $\mu \mathrm{m}$ sections, and deparaffinized with xylene. Antigen retrieval was performed by blocking with PBS containing $10 \%$ donkey serum for $1 \mathrm{~h}$. Tissues were incubated overnight at $4^{\circ} \mathrm{C}$ with the p-SAPK/JNK and p-c-Jun mouse monoclonal IgGs. Sections were incubated for $1 \mathrm{~h}$ at $37^{\circ} \mathrm{C}$ with the biotinylated anti-mouse secondary antibody (Vector Laboratories, Burlingame, CA, USA). The Vectastain Elite ABC reagent (Vector Laboratories) was added, and the formed antibody/ enzyme conjugate was visualized with addition of 3,3'-diaminobenzidine (DAB; Vector Laboratories). All sections were counterstained with hematoxylin and eosin (Sigma-Alrdich). For these analyses, six different HCC samples were evaluated per experimental condition.

Statistical analyses. A minimum of three replicates were performed for all experiments. Data were expressed as the mean \pm standard error. Comparisons between treated and control cell data were performed using Student's t-tests. P-values $<0.05$ was considered to indicate statistically significant differences.

\section{Results}

Cell survival, SP cell fraction, and p-SAPK/JNK expression upon 5-FU and paclitaxel treatment. To observe the effect of anticancer drugs, 5-FU or paclitaxel were administered to Huh7 cells for $72 \mathrm{~h}$, and the cell survival was assessed by cell counting after trypan blue staining. Huh7 cells exhibited a dose-dependent inhibition in survival following treatment with the anticancer drugs (Fig. 1, upper panels). The survival of Huh7 cells relative to that of untreated cells was $63 \%$ following treatment with $1 \mu \mathrm{M} \mathrm{5-FU} \mathrm{32 \%} \mathrm{with} 10 \mu \mathrm{M}$, and $22 \%$ with $100 \mu \mathrm{M}$ (Fig. 1A, upper panel). The survival of Huh7 cells relative to that of untreated cells was $73 \%$ after 
A
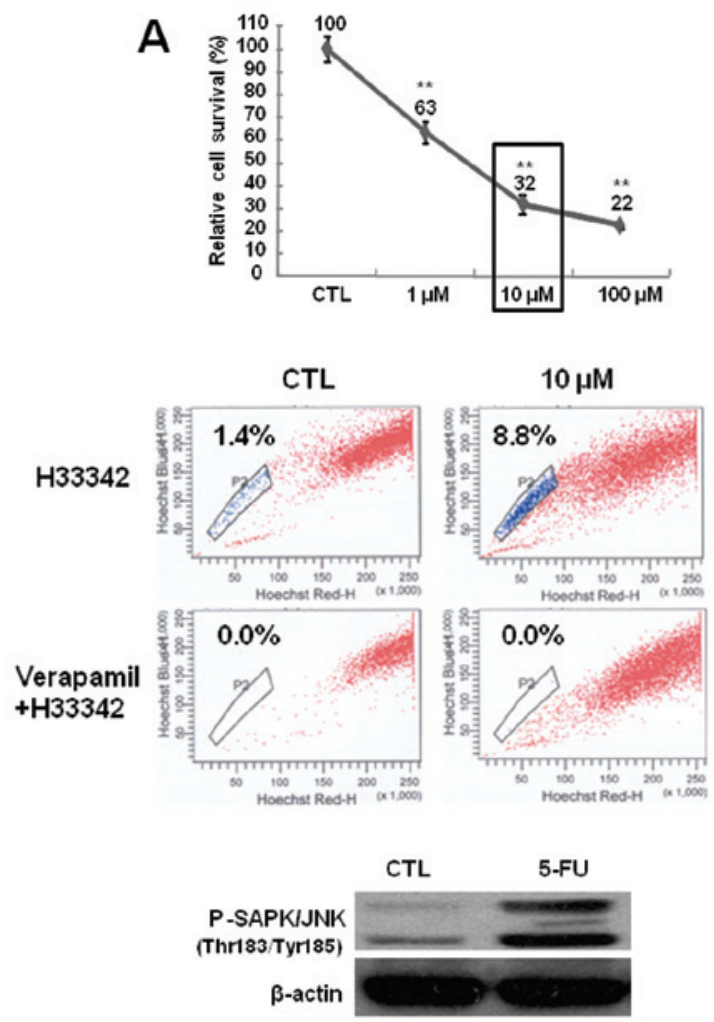

B
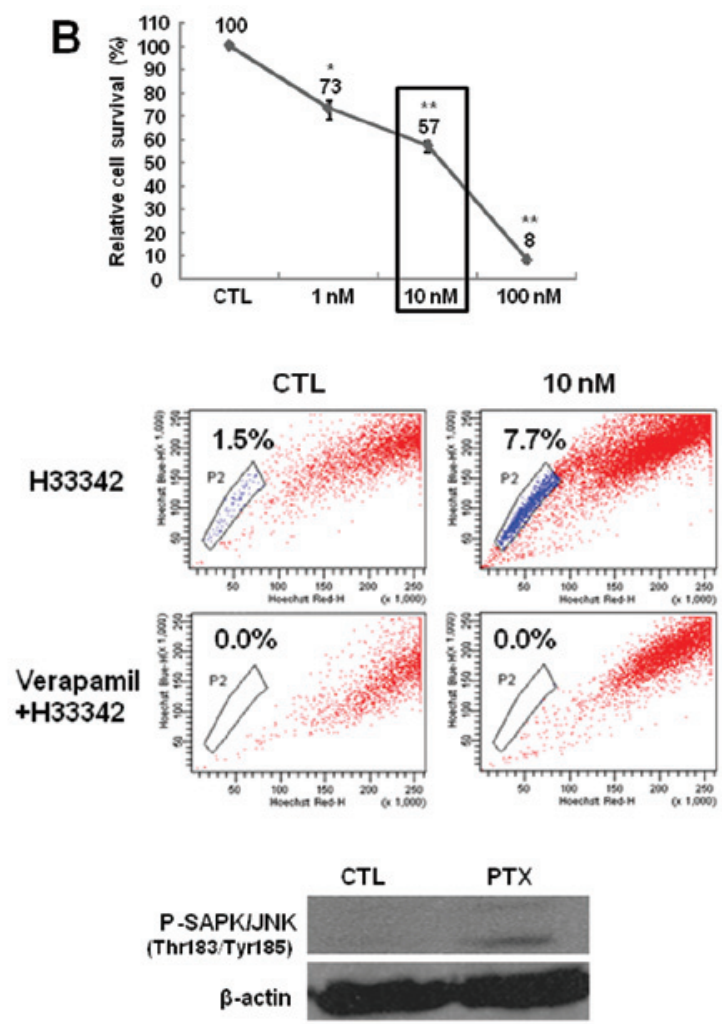

Figure 1. Cell survival rate, fraction of side population (SP) cells, and phospho-stress-activated protein kinase/c-Jun-N-terminal kinase (p-SAPK/JNK) expression in Huh7 cells after treatment with (A) 5-fluorouracil (5-FU) and (B) paclitaxel. Upper panels: cell survival was assessed by counting cells using trypan blue dye exclusion. Cells were treated with distilled water (CTL), 1, 10 or $100 \mu \mathrm{M} 5$-FU, or 1, 10 or $100 \mathrm{nM}$ paclitaxel for $72 \mathrm{~h}$. Survival rate is expressed as a percentage relative to that of control cells. ${ }^{*} \mathrm{P}<0.05,{ }^{* *} \mathrm{P}<0.01$ compared with the control and treated cells, respectively. Middle panels: for each group of cells, the percentage of SP cells is shown in the upper quadrant. Cells were treated with distilled water (CTL), $10 \mu \mathrm{M} 5$-FU, or $10 \mathrm{nM}$ paclitaxel for $72 \mathrm{~h}$. Lower panels: p-SAPK/JNK expression was detected by immunoblotting. Cells were treated with distilled water (CTL), $10 \mu \mathrm{M} 5$-FU, or $10 \mathrm{nM}$ paclitaxel for $72 \mathrm{~h}$. Representative blots $(\mathrm{n}=3)$ are shown. $\beta$-actin was used as the loading control.

treatment with $1 \mathrm{nM}$ paclitaxel, $57 \%$ with $10 \mathrm{nM}$, and $8 \%$ with $100 \mathrm{nM}$ (Fig. 1B, upper panel). Based on these results, we selected the doses of $10 \mu \mathrm{M} 5-\mathrm{FU}$ and $10 \mathrm{nM}$ paclitaxel to observe SP cells and the expression of JNK upon anticancer drug treatment.

Cells were treated with $10 \mu \mathrm{M} 5$-FU or $10 \mathrm{nM}$ paclitaxel for $72 \mathrm{~h}$. Drug treatment increased the SP cell number relative to untreated cells (Fig. 1, middle panels). The SP cell fraction was $1.4 \%$ in untreated cells, $2.6 \%$ in $1 \mu \mathrm{M}$ 5-FU-treated cells, $8.8 \%$ in $10 \mu \mathrm{M} 5$-FU-treated cells, and $3.9 \%$ in $100 \mu \mathrm{M} 5$-FU-treated cells (Fig. 1A, middle panel). The SP cell fraction was $1.5 \%$ in untreated cells, $2.4 \%$ in $1 \mathrm{nM}$ paclitaxel-treated cells, $7.7 \%$ in $10 \mathrm{nM}$ paclitaxel-treated cells, and $1.6 \%$ in $100 \mathrm{nM}$ paclitaxel-treated cells (Fig. 1B, middle panel). In addition, we observed JNK activation upon drug treatment. Both 5-FU and paclitaxel increased the level of p-SAPK/JNK (Fig. 1, lower panels). These results indicate that the increase in the SP cell fraction may be associated with JNK signaling.

The SP cell fraction decreases upon treatment with 5-FU and SP600125. To determine whether the increased number of SP cells observed after treatment with anticancer drugs can be reduced by inhibiting JNK, the SP fraction was evaluated in Huh7 and HepG2 cells treated for $72 \mathrm{~h}$ with 5-FU, SP600125 alone, or with both 5-FU and SP600125. The SP fraction increased upon 5-FU treatment, and this increase was blocked by SP600125 (Fig. 2). These results indicate that inhibiting
JNK signaling can block the increase in SP cells induced by anticancer drugs in liver cancer.

The JNK inhibitor SP600125 inhibits expression of $p$-SAPK/JNK upon 5-FU treatment. Treatment with anticancer drugs decreased the survival rate and increased the level of p-JNK and the number of SP cells. However, the increase in SP cells was blocked by the JNK inhibitor. To examine whether the JNK inhibitor also enhances cell survival or blocks upregulation of $\mathrm{p}-\mathrm{JNK}$, the relative survival rate and the JNK expression level were evaluated in Huh7 and HepG2 cells treated for $72 \mathrm{~h}$ with 5-FU, SP600125, or both 5-FU and SP600125. As shown in Fig. 3A, cell survival was decreased in all treated groups (5-FU, SP600125, or 5-FU + SP600125). SP600125 did not revert the inhibition on cell survival induced by 5-FU (Fig. 3A). However, SP600125 attenuated the 5-FU-mediated upregulation of p-SAPK/JNK, c-Jun, and p-c-Jun (Fig. 3B). These results indicate that the JNK inhibitor blocks the activation of JNK signaling mediated by 5-FU.

Expression of $p$-SAPK/JNK and p-c-Jun in healthy and hepatocarcinoma tissues. $\mathrm{p}-\mathrm{SAPK} / \mathrm{JNK}$ and $\mathrm{p}$-c-Jun expression was found to be increased upon treatment with anticancer drugs and blocked by the JNK inhibitor in the Huh-7 and HepG2 hepatocarcinoma cell lines. To determine the relationship between $\mathrm{p}$-SAPK/JNK and $\mathrm{p}$-c-Jun expression and the progression of hepatocarcinoma, we evaluated $\mathrm{p}-\mathrm{SAPK} / \mathrm{JNK}$ 
A
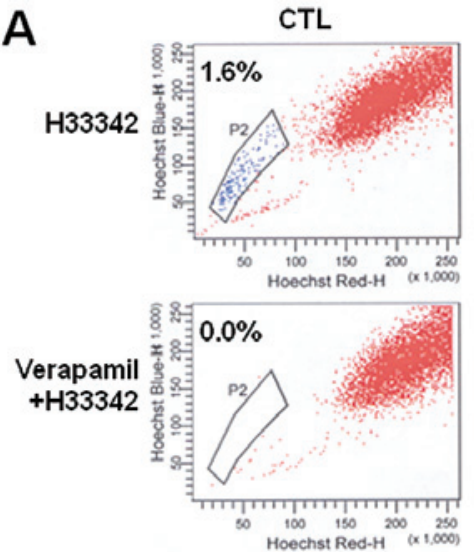

B
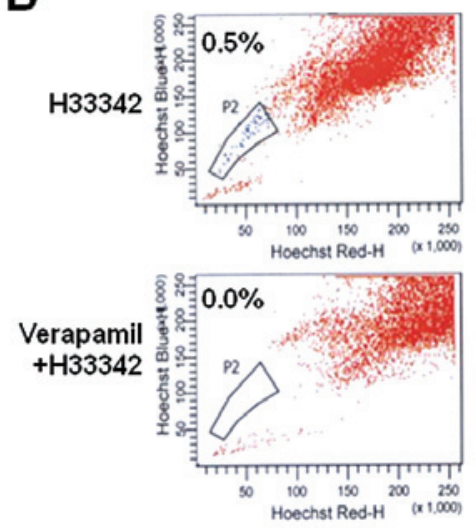

SP600125
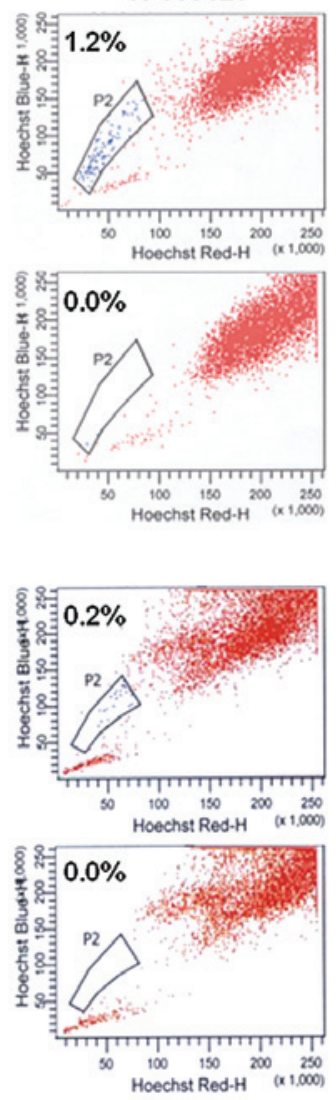

5-FU
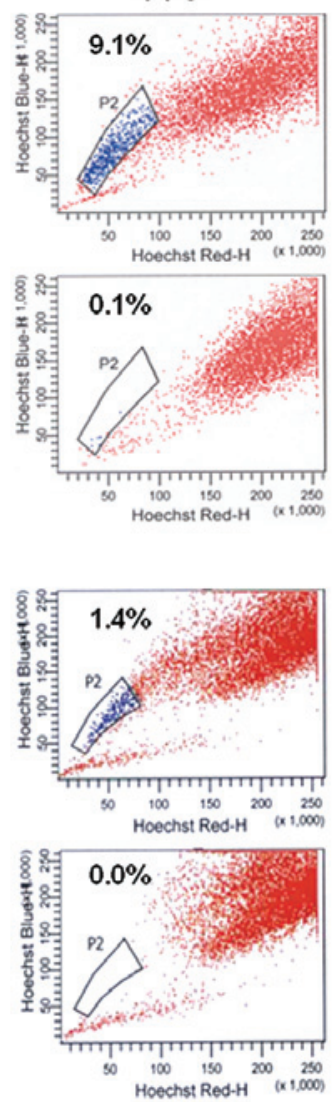

5-FU+P600125
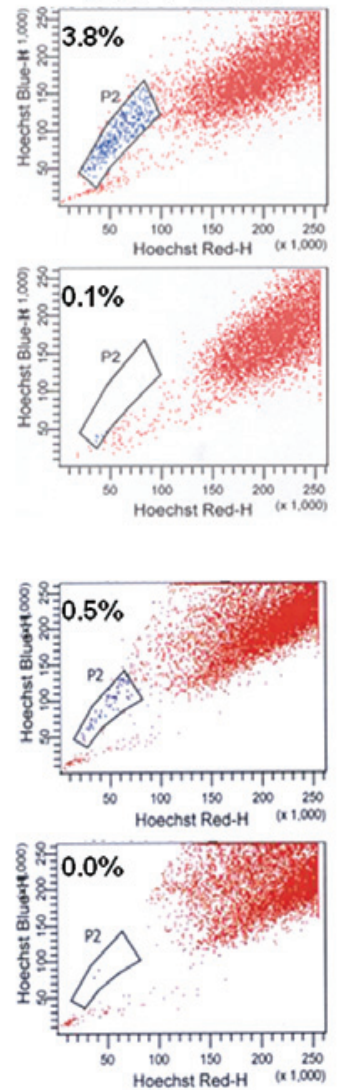

Figure 2. The side population (SP) cell fraction in (A) Huh7 and (B) HepG2 cells after 5-fluorouracil (5-FU) and SP600125 treatment. SP cells were assayed using a fluorescence-activated cell sorting (FACS) Aria instrument with a 515-nm side population filter (Hoechst blue). Huh7/HepG2 cells were treated with distilled water and dimethyl sulfoxide (CTL), $10 \mu \mathrm{M}$ 5-FU, $10 \mu \mathrm{M}$ SP600125, or $10 \mu \mathrm{M}$ 5-FU + $10 \mu \mathrm{M}$ SP600125 for $72 \mathrm{~h}$. H33342, Hoechst 33342 dye.

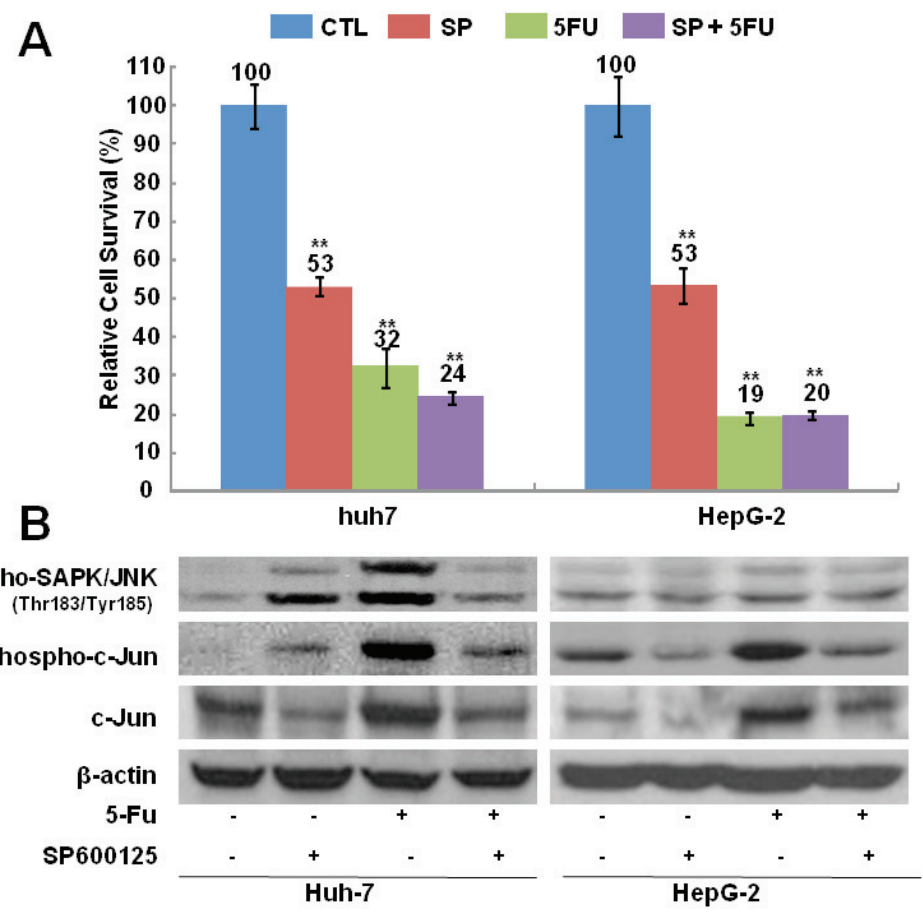

Figure 3. Cell survival rate and expression of phospho-stress-activated protein kinase/c-Jun-N-terminal kinase (p-SAPK/JNK), p-c-Jun, and c-Jun in Huh7 and HepG2 cells after 5-fluorouracil (5-FU) and SP600125 treatment. (A) Cell survival was assessed by counting cells using trypan blue dye exclusion. Cells were treated for $72 \mathrm{~h}$ with distilled water and dimethyl sulfoxide (DMSO; CTL), $10 \mu \mathrm{M} 5-\mathrm{FU}, 10 \mu \mathrm{M} \mathrm{SP} 600125$ (SP), or $10 \mu \mathrm{M} 5$-FU + $10 \mu \mathrm{M}$ SP600125. Survival rate is expressed as a percentage relative to that of control cells. Values represent the mean \pm standard error from at least three independent experiments. ${ }^{* *} \mathrm{P} \leq 0.05$. (B) Expression of p-JNK, p-c-Jun, c-Jun was detected by immunoblotting. Cells were treated with distilled water and DMSO (lane 1 from left), $10 \mu \mathrm{M}$

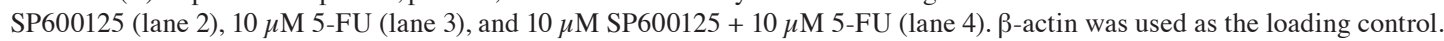




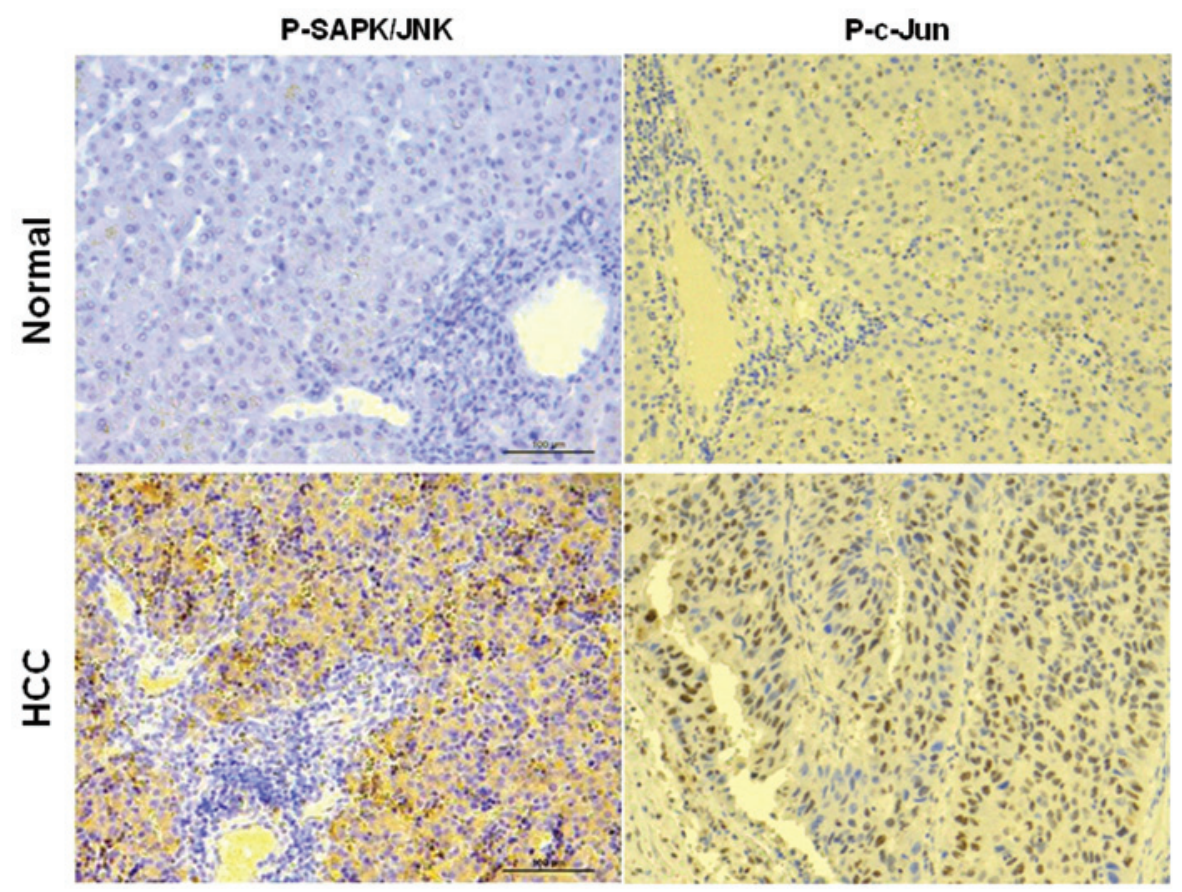

Figure 4. Phospho-stress-activated protein kinase/c-Jun-N-terminal kinase (p-SAPK/JNK) and p-c-Jun expression in healthy (normal) and hepatocellular carcinoma (HCC) tissues detected using immunohistochemistry. Six different HCC samples were evaluated per experimental condition.

and p-c-Jun expression in hepatocarcinoma tissues using immunohistochemistry. Expression of $\mathrm{p}-\mathrm{SAPK} / \mathrm{JNK}$ and p-c-Jun appeared high in hepatocarcinoma tissues (Fig. 4). These results indicate that JNK signaling may associate with hepatocarcinoma progression.

\section{Discussion}

Numerous studies have evaluated the increase in cancer stem cell number upon treatment with anticancer drugs, focusing on the relationship between drug resistance and cancer stem cells. In this study, we examined the SP cells, a model for the study of cancer stem cells, and the involvement of JNK signaling in liver cancer. To determine the relationship between cancer stem cells and JNK signaling after treatment with anticancer drugs, we examined the survival rate, SP cell ratio, and JNK expression in hepatocarcinoma cell lines after anticancer drug treatment. We observed that SP cells constitute a small subpopulation involved in drug resistance in liver cancer, and that the tested anticancer drugs decreased the survival rate and increased the SP fraction in two hepatocarcinoma cell lines.

Similar to our results, a number of studies have suggested that anticancer drugs do not target cancer stem cells, but instead increase the cancer stem cell fraction in liver cancer. Bonnet and Dick (17) reported that cancer cells include a small number of cells within a heterogeneous population, which have the ability to initiate tumor formation. Regarding drug resistance induced by cancer cell culturing, Sharma et al (18) reported that a small population of cancer cells exhibiting drug resistance propagated and increased in size after a long period of anticancer drug withdrawal. The authors suggested that acquisition of drug resistance and the maintenance of this drug-tolerant population involved activation of IGF-1R signaling and a distinct chromatin state (18).
To investigate the signaling pathways involved in the increased SP cell number, we evaluated the expression of JNK signaling molecules in hepatocarcinoma cell lines following treatment with anticancer drugs. JNK is also the main signaling pathway involved in maintaining the stemness of glioma cells (19). We found that the tested anticancer drugs increase the expression level of p-JNK in hepatocarcinoma cell lines, similar to a previous study (19). JNK expression was increased upon anticancer drug treatment and in hepatocarcinoma tissues. Based on these results, we simultaneously treated cells with a JNK inhibitor and the anticancer drugs and observed a blocking effect on the increased SP cell ratio and JNK expression. Similar to our results, another study indicated that JNK signaling is associated with the maintenance of cancer stem cells and drug resistance (13). With respect to the relationship between JNK signaling and drug resistance in liver cancer, Yan et al (12) suggested that JNK1, JNK2, and JNK3 maintain drug resistance by upregulating the P-glycoprotein. Nagata et al (20) also suggested that JNK signaling is involved in inhibiting hepatocarcinoma progression based on experiments using a JNK inhibitor (SP600125) and an animal model. Similar to our results, Mucha et al (21) showed that the JNK inhibitor (SP600125) inhibits cell growth and JNK activity.

JNK signaling is known to be involved in cancer progression in liver cancer (22). We found that JNK and c-Jun are highly expressed in hepatocarcinoma compared to healthy tissues. There is a number of reports on the expression of JNK in hepatocarcinoma. Wang et al (23) demonstrated that high p-p38 and low p-JNK expression is associated with poor survival in hepatocarcinoma tissues. Hagiwara et al (24) suggested that the high levels of JNK and c-Jun may be predictive biomarkers for the high risk of recurrence after surgery in non-cancerous liver tissue. These results indicate that JNK activity is involved in liver cancer progression. 
In conclusion, we showed that JNK activity is associated with an increase in the fraction of the side population cells upon treatment with anticancer drugs. Side population cells may be regulated by JNK signaling following anticancer drug treatment. JNK activity is involved in liver cancer progression. These results suggest that JNK signaling may be involved in the maintenance of cancer stem cells and the progression of liver cancer.

\section{Acknowledgements}

This study was supported by grants from the Hanmi Pharmatheutical Company (no. 800-20130024) and the Yunhan Corporation (no. 800-20130029).

\section{References}

1. Reya T, Morrison SJ, Clarke MF and Weissman IL: Stem cells, cancer, and cancer stem cells. Nature 414: 105-111,.2001.

2. Suetsugu A, Nagaki M, Aoki H, Motohashi T, Kunisada T and Moriwaki H: Characterization of CD133+ hepatocellular carcinoma cells as cancer stem/progenitor cells. Biochem Biophys Res Commun 351: 820-824, 2006.

3. Al-Hajj M, Wicha MS, Benito-Hernandez A, Morrison SJ and Clarke MF: Prospective identification of tumorigenic breast cancer cells. Proc Natl Acad Sci USA 100: 3983-3988, 2003.

4. Ponti D, Costa A, Zaffaroni N, Pratesi G, Petrangolini G, Coradini D, Pilotti S, Pierotti MA and Daidone MG: Isolation and in vitro propagation of tumorigenic breast cancer cells with stem/progenitor cell properties. Cancer Res 65: 5506-5511, 2005.

5. Setoguchi T, Taga T and Kondo T: Cancer stem cells persist in many cancer cell lines. Cell cycle 3:414-415, 2004.

6. Feuring-Buske $M$ and Hogge DE: Hoechst 33342 efflux identifies a subpopulation of cytogenetically normal CD34(+) CD38(-) progenitor cells from patients with acute myeloid leukemia. Blood 97: 3882-3889, 2001.

7. Uchida N, Fujisaki T, Eaves ACand Eaves CJ: Transplantable hematopoietic stem cells in human fetal liver have a CD34(+) side population (SP)phenotype. J Clini Invest 108: 1071-1077, 2001.

8. Ho MM, Ng AV, Lam S and Hung JY: Side population in human lung cancer cell lines and tumors is enriched with stem-like cancer cells. Cancer Res 67: 4827-4833, 2007.

9. Chiba T, Kita K, Zheng YW, Yokosuka O, Saisho H, Iwama A, Nakauchi $\mathrm{H}$ and Taniguchi $\mathrm{H}$; Side population purified from hepatocellular carcinoma cells harbors cancer stem cell-like properties. Hepatology 44: 240-251, 2006.

10. Zen Y, Fujii T, Yoshikawa S, Takamura H, Tani T, Ohta T and Nakanuma Y: Histological and culture studies with respect to ABCG2 expression support the existence of a cancer cell hierarchy in human hepatocellular carcinoma. Am J Pathol 170: $1750-1762,2007$.
11. Hu C, Li H, Li J, Zhu Z, Yin S, Hao X, Yao M, Zheng S and Gu J: Analysis of ABCG2 expression and side population identifies intrinsic drug efflux in the HCC cell line MHCC-97L and its modulation by Akt signaling. Carcinogenesis 29: 2289-2297, 2008.

12. Yan F, Wang XM, Liu ZC, Pan C, Yuan SB and Ma QM: JNK1, JNK2, and JNK3 are involved in P-glycoprotein-mediated multidrug resistance of hepatocellular carcinoma cells. Hepatobiliary Pancreat Dis Int 9: 287-295, 2010.

13. Sancho R, Nateri AS, de Vinuesa AG, Aguilera C, Nye E, Spencer-Dene B and Behrens A: JNK signalling modulates intestinal homeostasis and tumourigenesis in mice. EMBO J 28: 1843-1854, 2009.

14. Lu S, Shen KC, Wang Y, Brooks SC and Wang YA; Impaired hepatocyte survival and liver regeneration in Atm-deficient mice. Hum Mol Genet 14: 3019-3025, 2005.

15. Komoda F, Shino Y, Hirano T, Okutomi Y, Okamoto H, Hayashi Y, Suyama T, Ebara M, Saisho H and Shirasawa H: MEKK1 induces c-Jun complexes that act as negative regulators for cell survival and proliferation of HCC cells. Int J Oncol 21: 553-559, 2002.

16. Goodell MA: Multipotential stem cells and 'side population' cells. Cytotherapy 4:507-508, 2002.

17. Bonnet D and Dick JE: Human acute myeloid leukemia is organized as a hierarchy that originates from a primitive hematopoietic cell. Nat Med 3: 730-737, 2007.

18. Sharma SV, Lee DY, Li B, Quinlan MP, Takahashi F, Maheswaran S, McDermott U, Azizian N, Zou L, Fischbach MA, Wong KK, Brandstetter K, Wittner B, Ramaswamy S, Classon M and Settleman J: A chromatin-mediated reversible drug-tolerant state in cancer cell subpopulations. Cell 141: 69-80, 2010.

19. Yoon CH, Kim MJ, Kim RK, Lim EJ, Choi KS, An S, Hwang SG, Kang SG, Suh Y, Park MJ and Lee SJ: c-Jun N-terminal kinase has a pivotal role in the maintenance of self-renewal and tumorigenicity in glioma stem-like cells. Oncogene 31: 4655-4666, 2012.

20. Nagata H, Hatano E, Tada M, Murata M, Kitamura K, Asechi H, Narita M, Yanagida A, Tamaki N, Yagi S, Ikai I, Matsuzaki K and Uemoto S: Inhibition of c-Jun NH2-terminal kinase switches Smad3 signaling from oncogenesis to tumor- suppression in rat hepatocellular carcinoma. Hepatology 49: 1944-1953, 2009.

21. Mucha SR, Rizzani A, Gerbes AL, Camaj P, Thasler WE, Bruns CJ, Eichhorst ST, Gallmeier E, Kolligs FT, Goke B and De Toni EN: JNK inhibition sensitises hepatocellular carcinoma cells but not normal hepatocytes to the TNF-related apoptosisinducing ligand. Gut 58: 688-698, 2009.

22. Seki E, Brenner DA and Karin M: A liver full of JNK: signaling in regulation of cell function and disease pathogenesis, and clinical approaches. Gastroenterology 143: 307-320, 2012

23. Zhang DM, Shu C, Chen JJ, Sodani K, Wang J, Bhatnagar J, Lan P, Ruan ZX, Xiao ZJ, Ambudkar SV, Chen WM, Chen ZS and Ye WC: BBA, a derivative of 23-hydroxybetulinic acid, potently reverses $\mathrm{ABCB} 1$-mediated drug resistance in vitro and in vivo. Mol Pharm 9:3147-3159, 2012.

24. Hagiwara S, Kudo M, Chung H, Ueshima K, Inoue T, Haji S, Watanabe T, Park AM, Munakata H, Sakurai T. 2012. Activation of c-Jun N-terminal kinase in non-cancerous liver tissue predicts a high risk of recurrence after hepatic resection for hepatocellular carcinoma. Hepatol Res 42:394-400., 2012. 